OPEN ACCESS

Edited by:

Susan Christina Welburn,

University of Edinburgh,

United Kingdom

Reviewed by:

Xiaojiong Jia,

Harvard Medical School,

United States

Ali Teimoori

Hamadan University of Medical

Sciences, Iran

*Correspondence:

Francisco González-Salazar fgonz75@hotmail.com

Specialty section:

This article was submitted to Infectious Diseases - Surveillance,

Prevention and Treatment, a section of the journal

Frontiers in Public Health

Received: 23 December 2020 Accepted: 08 June 2021

Published: 05 July 2021

Citation:

Cordero-Franco HF, De La Garza-Salinas LH, Gomez-Garcia S,

Moreno-Cuevas JE, Vargas-Villarreal $J$ and González-Salazar F (2021) Risk Factors for SARS-CoV-2 Infection, Pneumonia, Intubation, and Death in Northeast Mexico.

Front. Public Health 9:645739. doi: 10.3389/fpubh.2021.645739

\section{Risk Factors for SARS-CoV-2 Infection, Pneumonia, Intubation, and Death in Northeast Mexico}

\author{
Hid Felizardo Cordero-Franco ${ }^{1,2}$, Laura Hermila De La Garza-Salinas ${ }^{3}$, \\ Salvador Gomez-Garcia ${ }^{4}$, Jorge E. Moreno-Cuevas ${ }^{5}$, Javier Vargas-Villarreal ${ }^{2}$ and \\ Francisco González-Salazar ${ }^{2,5 *}$ \\ 1 Unidad de Investigación Epidemiológica y en Servicios de Salud, Delegación Nuevo León, Instituto Mexicano del Seguro \\ Social, Monterrey, Mexico, ${ }^{2}$ Centro de Investigaciones Biomédicas Del Noreste, Instituto Mexicano Del Seguro Social, \\ Monterrey, Mexico, ${ }^{3}$ Planeación y Enlace Institucional, Delegación Regional Nuevo León, Instituto Mexicano del Seguro \\ Social, Monterrey, Mexico, ${ }^{4}$ Coordinación de Información y Análisis estratégico, Delegación Regional Nuevo León, Instituto \\ Mexicano del Seguro Social, Monterrey, Mexico, ${ }^{5}$ División de Ciencias de La Salud, Departamento de Ciencias Básicas, \\ Universidad de Monterrey, Monterrey, Mexico
}

Despite the social distancing and mobility restriction measures implemented for susceptible people around the world, infections and deaths due to COVID-19 continued to increase, even more so in the first months of 2021 in Mexico. Thus, it is necessary to find risk groups that can benefit from more aggressive preventive measures in a high-density population. This is a case-control study of suspected COVID-19 patients from Nuevo León, Mexico. Cases were: (1) COVID-19-positive patients and COVID-19-positive patients who (2) developed pneumonia, (3) were intubated and (4) died. Controls were: (1) COVID-19-negative patients, (2) COVID-19-positive patients without pneumonia, (3) non-intubated COVID-19-positive patients and (4) surviving COVID-19-positive patients. $\geq 18$ years of age, not pregnant, were included. The pre-existing conditions analysed as risk factors were age (years), sex (male), diabetes mellitus, hypertension, chronic obstructive pulmonary disease, asthma, immunosuppression, obesity, cardiovascular disease, chronic kidney disease and smoking. The Mann-Whitney $U$ tests, Chi square and binary logistic regression were used. A total of 56,715 suspected patients were analysed in Nuevo León, México, with $62.6 \%$ being positive for COVID-19 and, of those infected, 14\% developed pneumonia, $2.9 \%$ were intubated and $8.1 \%$ died. The mean age of those infected was 44.7 years, while of those complicated it was around 60 years. Older age, male sex, diabetes, hypertension, and obesity were risk factors for infection, complications, and death from COVID-19. This study highlights the importance of timely recognition of the population exposed to pre-existing conditions to prioritise preventive measures against the virus.

Keywords: COVID-19, SARS-CoV-2, coronavirus, pneumonia, intubation endotracheal, death, Mexico 


\section{INTRODUCTION}

Currently, coronavirus disease 2019 (COVID-19) is a global public health problem. As of May 10, 2021, 158,551,526 people have been infected and 3,296,855 have died from this disease worldwide (1). The situation is no less dire in Mexico, where 2,366,496 infected people and 219,089 deaths have been documented (2). Since the World Health Organization (WHO) first declared COVID-19 a pandemic (3), and given the absence of a vaccine and effective treatment at that time, several studies have been conducted to determine the factors associated with severity and mortality. These studies demonstrated that older age and certain chronic conditions such as diabetes, hypertension and obesity, among others, were associated with higher risks of complications and death (4-9). Given the above findings, many countries, including Mexico, implemented preventive strategies aimed at reducing the exposure of vulnerable people, such as social distancing of the elderly and people with chronic diseases, closure of non-essential companies and schools, limits on the number of people in stores and essential establishments, educational reinforcement of handwashing and the use of face masks. These measures aimed to reduce the rate of infections and subsequently the mortality associated with the causal virus, however, they had significant growth in January and February of 2021 (1). Furthermore, a recently published North American study was unable to identify reductions in mortality during restricted mobility days in either the United States or Europe (10). The lack of control of the rates of infection and death is a clear example that there is much we still do not understand about the transmissibility of COVID-19 since many people around the world continue becoming infected and infecting others.

Nuevo León is a state of Mexico with a population density greater than the national average (11). It is a highly industrialised region that includes approximately 2.54 million economically active people (12). The closure of many productive activities due to the pandemic caused the loss of thousands of jobs, which triggered a growth in informal economic activities (13). In many cases, these circumstances prevented home office work, which could cause greater exposure to infected people and a greater spread of COVID-19 in this population (14). Moreover, this state has a high prevalence of chronic diseases such as obesity, diabetes and hypertension (15), which have consistently been associated with infection $(16,17)$ and worse outcomes in the course of this disease (4-9, 18, 19).

Therefore, it is imperative to determine not only the factors associated with a worse outcome of this disease but also those related to infection. This knowledge is necessary in a high-density population to establish risk groups that could benefit from more aggressive preventive measures, including vaccines.

The aim of this work was to determine the risk factors associated with COVID-19 infection and to determine the risk factors for pneumonia, intubation and death among those infected with COVID-19.

\section{MATERIALS AND METHODS}

\section{Study Population}

The data from patients in Nuevo León, Mexico, with suspected COVID-19 were obtained from the open access database of the General Directorate of Epidemiology of the Ministry of Health. The database contains data from all health institutions in Mexico. For this study, data collected from February 11, 2020 to September 24, 2020 were analysed (20).

\section{Groups and Study Goals}

Cases were defined as follows: (1) COVID-19-positive patients and COVID-19-positive patients who (2) developed pneumonia, (3) were intubated and (4) died. The respective controls were (1) COVID-19-negative patients, (2) COVID-19-positive patients without pneumonia, (3) non-intubated COVID-19positive patients and (4) surviving COVID-19-positive patients. The sample size for each study objective was sufficient to identify odds ratios of 1.14-1.47 with a confidence level of $95 \%$ and a statistical power of $100 \%$ (see Supplementary Figure 1 for a more detailed description of the size of each study group).

\section{Procedures}

Patients aged $\geq 18$ years who were treated in Nuevo León, Mexico, were included; pregnant patients were excluded $(n=$ 513). Pre-existing conditions analysed included those previously identified as risk factors for COVID-19 and its complications: age (years), sex (male), diabetes mellitus, hypertension, chronic obstructive pulmonary disease, asthma, immunosuppression, obesity, cardiovascular disease, chronic kidney disease and smoking $(4-9,18,19)$. The following outcomes were evaluated: COVID-19 infection [severe acute respiratory syndrome coronavirus 2 (SARS-CoV-2) polymerase chain reactionpositive], COVID-19 pneumonia, COVID-19 intubation and COVID-19 death. Except for age, all variables were coded in a categorical binary method (Yes vs. No). The following data were also analysed: medical care institution (public or private), origin from the metropolitan area and hospitalisation.

\section{Ethical Considerations}

This protocol was subject to the institutional, national and international norms and regulations on research and ethics in health and was approved by the Local Committee on Ethics and Health Research of the Mexican Institute of Social Security No. 1909 and registered as R-2020-1909-027. In this study, an open access database available on the internet was managed, and non-personal information of the study patients was obtained or recorded.

\section{Statistical Analysis}

The measures of central tendency and proportions, as well as $95 \%$ confidence intervals, were estimated. The Mann-Whitney $U$ test was used to compare age between independent groups after the Kolmogorov-Smirnov test verified the non-normal distribution of variables. Univariate and multivariate odds ratios were 
TABLE 1 | General data, comorbidities and outcomes of patients analysed for SARS-CoV-2 in Nuevo León (February to September 2020).

\begin{tabular}{|c|c|c|}
\hline & $N=56,715$ & $\%$ \\
\hline Live in metropolitan area & 48,274 & $85.1 \%$ \\
\hline \multicolumn{3}{|l|}{ Gender } \\
\hline Female & 27,608 & $48.7 \%$ \\
\hline Male & 29,107 & $51.3 \%$ \\
\hline \multicolumn{3}{|l|}{ Institution } \\
\hline Public & 53,709 & $94.7 \%$ \\
\hline Private & 3,006 & $5.3 \%$ \\
\hline \multicolumn{3}{|l|}{ Comorbidities } \\
\hline Hypertension & 9,489 & $16.7 \%$ \\
\hline Obesity & 8,504 & $15.0 \%$ \\
\hline Diabetes mellitus & 7,874 & $13.9 \%$ \\
\hline Smoking & 4,627 & $8.2 \%$ \\
\hline Asthma & 1,536 & $2.7 \%$ \\
\hline Another comorbidity & 1,405 & $2.5 \%$ \\
\hline Cardiovascular disease & 1,165 & $2.1 \%$ \\
\hline Chronic kidney disease & 897 & $1.6 \%$ \\
\hline Immunosuppression & 700 & $1.2 \%$ \\
\hline COPD & 491 & $0.9 \%$ \\
\hline COVID-19 positive patients & 35,476 & $62.6 \%$ \\
\hline Pneumonia & 4,974 & $14.0 \%$ * \\
\hline Hospitalised & 7,351 & $20.7 \%$ * \\
\hline Intubated & 1,021 & $2.9 \% *$ \\
\hline Dead & 2,860 & $8.1 \% *$ \\
\hline
\end{tabular}

COPD, chronic obstructive pulmonary disease. *Proportions of all COVID-19 positive patients.

estimated using Chi-square tests and binary logistic regressions, respectively. A $p$-value $<0.05$ was considered significant.

\section{RESULTS}

From the beginning of the pandemic until September 24, 2020, 56,715 patients with suspected COVID-19 were registered in Nuevo León, of whom $85.1 \%$ lived in the metropolitan area. The most frequent comorbidity was hypertension, followed by obesity. Of the total population analysed, $62.6 \%$ were positive for COVID-19, and of these, $14 \%$ developed pneumonia, $20.7 \%$ were hospitalised, $2.9 \%$ were intubated and $8.1 \%$ died (Table 1).

The mean age of the infected patients was 44.7 years, whereas the mean ages of those who developed pneumonia, were intubated, or died were $57.5,60.1$, and 63.6 years, respectively. In all comparisons, the cases were older than the controls (Table 2).

At the univariate level, male sex, diabetes, hypertension, and obesity were shown to be significantly associated with the risk of COVID-19 infection, pneumonia, intubation and death. Conversely, chronic obstructive pulmonary disease, immunosuppression, cardiovascular disease and chronic kidney disease showed a protective effect against COVID-19 infection, but were risk factors for pneumonia and death, while smoking was a protective factor against infection and those complications.
TABLE 2 | Comparison of patient age related to the main output variables.

\begin{tabular}{lccc}
\hline & $\begin{array}{c}\text { Mean age } \\
\text { (years) }\end{array}$ & Cl 95\% & P-value \\
\hline COVID-19 positive & 44.7 & $44.6-44.9$ & $<0.0001$ \\
COVID-19 negative & 42.2 & $42.0-42.4$ & \\
Pneumonia & 57.5 & $57.1-57.9$ & $<0.0001$ \\
No Pneumonia & 42.1 & $41.9-42.2$ & \\
Intubated & 60.1 & $59.3-60.9$ & $<0.0001$ \\
No Intubated & 57.2 & $56.8-57.5$ & \\
Dead & 63.6 & $63.1-64.0$ & $<0.0001$ \\
Survivors & 42.6 & $42.4-42.7$ & \\
\end{tabular}

Cl, confidence interval.

Asthma showed a protective effect against infection but did not show any association with complications (Table 3 ).

The multivariate level showed similar trends to those of the univariate analysis: male sex, diabetes mellitus, hypertension and obesity were risk factors for COVID-19 infection, whereas older age also showed an association, but this association was only marginal (odds ratio, 1.01; 95\% confidence interval, 1.001.02). These factors also showed a consistent risk association for complications, that is, pneumonia, intubation (except for diabetes) and death. Conversely, factors that were protective against COVID-19 infection did not show an association with complications (such as chronic obstructive pulmonary disease, asthma, and cardiovascular disease) or were risk factors for pneumonia and death (immunosuppression and chronic kidney disease); smoking was also protective against death (Table 4).

\section{DISCUSSION}

This study, which is based on a large representative database, examines pre-existing factors associated with COVID-19 infection as well as pneumonia, intubation, and death in northern Mexico. The main risk factors for infection and its complications were older age, male sex, hypertension, and obesity. Thus, it is possible to stratify patients exposed to these conditions to reinforce preventive and therapeutic strategies.

The population analysed in this study primarily corresponds to the metropolitan area of Nuevo León, a region with a high population density (11), which is a determining factor in the risk of contagion (21). Compared with another study performed in the total Mexican population, Nuevo León registered a higher proportion of positive cases of COVID-19 (62.6 vs. 52.6\%) (6). However, the rate of hospitalisations in this state was lower than that reported in the previous study (35.3\%) (6), which may be due to the fact that many outpatient diagnostic tests were performed in this state.

An important finding of this study is the mean age of the infected patients, which was younger than that of those who developed complications. This agrees with the estimates of Xiong et al. (14) in California, who found that the highest infection rate was in the population aged 18-59 years, that is, the economically active population, but there was a higher fatality rate in the 
TABLE 3 | Univariate analysis of pre-existing conditions associated with confirmed COVID-19 infection, pneumonia, intubation, and death.

\begin{tabular}{|c|c|c|c|c|}
\hline Output variable & COVID-19 positive & Pneumonia & Intubation & Death \\
\hline Pre-existing conditions & OR (Cl 95\%) & OR (Cl 95\%) & OR (Cl 95\%) & OR (Cl 95\%) \\
\hline Male & $1.17(1.13-1.21)^{\star \star}$ & $1.45(1.36-1.54)^{\star \star}$ & $1.14(0.99-1.31)$ & $1.47(1.36-1.59)^{\star \star}$ \\
\hline Diabetes mellitus & $1.59(1.51-1.68)^{\star \star}$ & $3.75(3.50-4.00)^{\star \star}$ & $1.21(1.05-1.38)^{\star}$ & $4.17(3.85-4.53)^{\star \star}$ \\
\hline COPD & $0.63(0.53-0.75)^{\star \star}$ & $4.09(3.18-5.28)^{\star \star}$ & 1.01 (0.64-1.60) & $5.74(4.40-7.48)^{\star \star}$ \\
\hline Asthma & $0.64(0.58-0.71)^{\star \star}$ & 1.02 (0.83-1.24) & $1.10(0.71-1.70)$ & $0.97(0.75-1.26)$ \\
\hline Immunosuppression & $0.51(0.44-0.60)^{\star \star}$ & $2.26(1.77-2.89)^{\star \star}$ & $1.41(0.93-2.13)$ & $2.89(2.20-3.80)^{\star \star}$ \\
\hline Hypertension & $1.40(1.34-1.47)^{\star \star}$ & $3.68(3.44-3.92)^{\star \star}$ & $1.40(1.22-1.60)^{\star \star}$ & $4.85(4.48-5.25)^{\star \star}$ \\
\hline Cardiovascular disease & $0.74(0.66-0.83)^{\star \star}$ & $3.48(2.95-4.10)^{\star \star}$ & 1.13 (0.83-1.53) & $4.16(3.47-4.98)^{\star \star}$ \\
\hline Obesity & $1.69(1.61-1.78)^{\star \star}$ & $1.71(1.60-1.84)^{\star \star}$ & $1.35(1.17-1.56)^{\star \star}$ & $1.74(1.59-1.90)^{\star *}$ \\
\hline Chronic kidney disease & $0.83(0.72-0.94)^{\star}$ & $5.49(4.61-6.54)^{\star \star}$ & $1.30(0.97-1.75)$ & $7.43(6.20-8.91)^{\star \star}$ \\
\hline Smoking & $0.78(0.73-0.83)^{\star \star}$ & $0.81(0.72-0.92)^{\star}$ & $1.17(0.90-1.52)$ & $0.82(0.70-0.96)^{\star}$ \\
\hline
\end{tabular}

OR, odds ratio; $\mathrm{Cl}$, confidence interval; COPD, chronic obstructive pulmonary disease. ${ }^{*} p<0.05$; ** $p<0.0001$.

TABLE 4 | Multivariate analysis of pre-existing conditions associated with confirmed COVID-19 infection, pneumonia, intubation, and death.

\begin{tabular}{|c|c|c|c|c|}
\hline Outcome variable & COVID-19 positive & Pneumonia & Intubated & Death \\
\hline Pre-existing conditions & OR (Cl 95\%) & OR (Cl 95\%) & OR (Cl 95\%) & OR (Cl 95\%) \\
\hline Age (risk for each year added) & $1.01(1.00-1.02)^{\star \star}$ & $1.06(1.05-1.07)^{\star \star}$ & $1.01(1.00-1.02)^{\star \star}$ & $1.08(1.07-1.09)^{\star *}$ \\
\hline Male & $1.21(1.17-1.25)^{\star \star}$ & $1.65(1.54-1.76)^{\star \star}$ & $1.23(1.07-1.41)^{\star}$ & $1.74(1.59-1.89)^{\star \star}$ \\
\hline Diabetes mellitus & $1.38(1.30-1.46)^{\star \star}$ & $1.65(1.53-1.79)^{\star \star}$ & $1.04(0.89-1.20)$ & $1.52(1.38-1.68)^{\star \star}$ \\
\hline COPD & $0.53(0.44-0.63)^{\star \star}$ & $1.13(0.85-1.49)$ & $0.83(0.51-1.33)$ & $1.29(0.95-1.74)$ \\
\hline Asthma & $0.66(0.59-0.73)^{\star \star}$ & $1.18(0.95-1.47)$ & $1.10(0.70-1.72)$ & $1.17(0.88-1.57)$ \\
\hline Immunosuppression & $0.48(0.41-0.55)^{\star \star}$ & $1.48(1.13-1.94)^{\star}$ & $1.46(0.96-2.22)$ & $1.92(1.41-2.61)^{\star \star}$ \\
\hline Hypertension & $1.11(1.05-1.17)^{\star \star}$ & $1.27(1.17-1.38)^{\star \star}$ & $1.20(1.03-1.39)^{\star}$ & $1.43(1.30-1.57)^{\star \star}$ \\
\hline Cardiovascular disease & $0.59(0.52-0.67)^{\star \star}$ & $1.11(0.92-1.33)$ & $0.90(0.66-1.24)$ & $1.02(0.83-1.26)$ \\
\hline Obesity & $1.67(1.58-1.76)^{\star *}$ & $1.56(1.44-1.70)^{\star *}$ & $1.40(1.20-1.63)^{\star \star}$ & $1.63(1.48-1.81)^{\star *}$ \\
\hline Chronic kidney disease & $0.65(0.57-0.75)^{\star \star}$ & $2.23(1.83-2.72)^{\star \star}$ & $1.14(0.84-1.55)$ & $2.86(2.32-3.53)^{\star \star}$ \\
\hline Smoke & $0.76(0.71-0.81)^{\star \star}$ & $0.81(0.71-0.93)^{\star}$ & $1.08(0.82-1.42)$ & $0.81(0.68-0.97)^{\star}$ \\
\hline
\end{tabular}

OR, odds ratio; $\mathrm{Cl}$, confidence interval; COPD, chronic obstructive pulmonary disease. ${ }^{\star} p<0.05 ;{ }^{\star *} p<0.0001$.

population aged $\geq 60$ years. In accordance with this finding, the higher infection rate in younger individuals seems to be related to the need to work outside home (14), whereas the higher severity and lethality seems to be explained by immunosenescence, a chronic low-grade systemic inflammation that has been proposed as a common factor resulting in greater susceptibility to COVID19 severity (22).

Another factor consistently associated with infection and severity was male sex. In this regard, men have been described as having biological and behavioural differences that place them at a higher risk than women, such as their higher level of testosterone that inhibits antibody production, the higher presence of receptors of angiotensin-converting enzyme 2 that facilitate viral anchorage and replication, insufficient handwashing practices, non-adherence to health services and reluctance to follow public health measures $(17,23-25)$.

In this population, pre-existing conditions did not equally affect the risks of infection, pneumonia, intubation, and death. Notably, chronic obstructive pulmonary disease, asthma, cardiovascular disease and even smoking showed protective effects against infection but did not show any association with complications or, as in the case of smoking, this was a "protective" factor against death. More remarkable still, factors such as immunosuppression and chronic kidney disease, which acted as protectors against infection, increased the risk of pneumonia and death. This contradiction could be explained because, as mentioned before, the Mexican health authorities implemented quarantine measures for the vulnerable population, which most likely made these groups under-represented in this database. In other words, it is not necessarily true that having such comorbidities offers any protection against COVID-19 but rather that the susceptible population was less exposed to the virus. In fact, diabetes, immunosuppression and chronic kidney disease, three serious medical conditions, have been reported to increase the risk of severity and death from COVID-19 (6, 9, 26). Therefore, preventive measures should be continued and reinforced in patients with these comorbidities.

An increased risk of infection became apparent among people with diabetes, hypertension, and obesity. Additionally, these comorbidities were risk factors for pneumonia, intubation (not 
diabetes) and death. This triad of comorbidities has already been described as a risk factor for adverse outcomes from COVID$19(6,9,27)$. At this point, it is necessary to emphasise the role of these chronic diseases in susceptibility to contagion. Yadav et al. had already pointed out this relationship in the Mumbai population and noted that the concurrence of these chronic diseases was strongly associated with COVID-19 infection (16). The biological explanation is that these comorbidities can lead to the overexpression of SARS-CoV-2 receptor molecules, such as angiotensin-converting enzyme 2 and CD147 (17). The practical implication of this relationship is that in a high-density population, with a high prevalence of these comorbidities, the risk of spreading the virus, even with social distancing measures, is extremely high. These findings emphasise the need to prioritise preventive measures such as vaccination in the potentially more vulnerable groups.

A limitation of this study is its use of a secondary data source. Thus, it is possible that some data were under-represented; therefore, the results shown should be viewed with caution. However, a strength of this study is that it included almost $100 \%$ of the data in a highly industrialised area with a high population density.

In conclusion, older age, male sex, hypertension, and obesity were factors consistently associated with COVID-19 infection as well as its complications, including pneumonia, intubation and death. Additionally, diabetes mellitus, immunosuppression and chronic kidney disease were identified as risk factors for pneumonia and death from COVID-19. This study highlights the importance of timely recognition of the population exposed to pre-existing conditions to prioritise preventive measures against the virus, such as mass vaccination.

\section{DATA AVAILABILITY STATEMENT}

The datasets presented in this study can be found in online repositories. The names of the repository/repositories and

\section{REFERENCES}

1. World Health Organization. WHO Coronavirus disease (COVID-19) dashboard. Situation Updates. (2021). Available online at: https://covid19. who.int/ (accessed May 12, 2021).

2. Johns Hopkins University C for SS and E. COVID-19 Dashboard. Coronavirus Resource Center. (2021). Available online at: https://coronavirus.jhu.edu/map. html (accessed May 12, 2021).

3. World Health Organization. Coronavirus disease 2019. (COVID-19) Situation Report--51. (2020). Available online at: https://www.who.int/docs/defaultsource/coronaviruse/situation-reports/20200311-sitrep-51-covid-19.pdf (accessed November 16, 2020).

4. Li X, Xu S, Yu M, Wang K, Tao Y, Zhou Y, et al. Risk factors for severity and mortality in adult COVID-19 inpatients in Wuhan. J Allergy Clin Immunol. (2020) 146:110-8. doi: 10.1016/j.jaci.2020.04.006

5. Xu PP, Tian RH, Luo S, Zu ZY, Fan B, Wang XM, et al. Risk factors for adverse clinical outcomes with COVID-19 in China: a multicenter, retrospective, observational study. Theranostics. (2020) 10:637283. doi: 10.7150/thno.46833

6. Hernández-Galdamez DR, González-Block MÁ, Romo-Dueñas DK, LimaMorales R, Hernández-Vicente IA, Lumbreras-Guzmán M, et al. Increased accession number(s) can be found at: COVID-19 open access database of the General Directorate of Epidemiology of the Ministry of Health.

\section{ETHICS STATEMENT}

The studies involving human participants were reviewed and approved by 1909-Local Committee of ethics on research, Mexican Institute of Social Security, Monterrey, Nuevo Leon, Mexico. Written informed consent for participation was not required for this study in accordance with the national legislation and the institutional requirements.

\section{AUTHOR CONTRIBUTIONS}

HC-F: data analysis, elaboration, and review of manuscript. FG-S: wrote protocol, wrote manuscript manage data, traduction, edition, and review final version. JV-V: design protocol, registry, and review final version. JM-C: design protocol, discussion, and review manuscript final. SG-G: get data, manage variables, and review final version manuscript. LD: registry protocol, get data, and review of final manuscript. All authors contributed to the article and approved the submitted version.

\section{ACKNOWLEDGMENTS}

The authors must thank to University of Monterrey and Mexican Institute of Social Security for the support provided for the completion and publication of this work.

\section{SUPPLEMENTARY MATERIAL}

The Supplementary Material for this article can be found online at: https://www.frontiersin.org/articles/10.3389/fpubh. 2021.645739/full\#supplementary-material risk of hospitalization and death in patients with COVID-19 and pre-existing non-communicable diseases and modifiable risk factors in Mexico. Arch Med Res. (2020) 22:683-9. doi: 10.1016/j.arcmed.2020.07.003

7. Liu D, Cui P, Zeng S, Wang S, Feng $\mathrm{X}, \mathrm{Xu} \mathrm{S}$, et al. Risk factors for developing into critical COVID-19 patients in Wuhan, China: a multicenter, retrospective, cohort study. EClinicalMedicine. (2020) 25:100471. doi: 10.1016/j.eclinm.2020.100471

8. Wu R, Ai S, Cai J, Zhang S, Qian ZM, Zhang Y, et al. Predictive model and risk factors for case fatality of COVID-19: a cohort of 21,392 cases in Hubei, China. Innovation. (2020) 1:100022. doi: 10.1016/j.xinn.2020.100022

9. Williamson EJ, Walker AJ, Bhaskaran K, Bacon S, Bates C, Morton CE, et al. Factors associated with COVID-19-related death using OpenSAFELY. Nature. (2020) 584:430-6. doi: 10.1038/s41586-020-2521-4

10. Mccafferty S, Ashley S. Covid-19 social distancing interventions by statutory mandate and their observational correlation to mortality in the United States and Europe. Pragmat Obs Res. (2021) 27:15-24. doi: 10.2147/POR.S298309

11. Instituto Nacional de Estadística Geografía e Informática. Densidad de población de Nuevo León. Cuéntame: Información por entidad. (2020). Available online at: http://www.cuentame.inegi.org.mx/monografias/ informacion/nl/poblacion/densidad.aspx?tema $=$ me\&e $=19 \#: \$$ sim $\$:$ text $=$ Nuevo León\&text=Por su densidad de población,lugar $14 \mathrm{a}$ nivel 
nacional.\&text=hay 61 personas por kilómetro cuadrado (accessed May 12, 2021).

12. Rivera E, Bárcenas A. Tiene Nuevo León relevancia para la economía nacional. El Financiero. (2020). Available online at: https://www.elfinanciero.com. $\mathrm{mx} / \mathrm{monterrey/tiene-nuevo-leon-relevancia-para-la-economia-nacional/}$ (accessed May 12, 2021).

13. Gobierno del Estado de Nuevo León. Impacto económico en Nuevo León ante COVID-19. Actualidad. (2020). Available online at: https://www.nl.gob.mx/ publicaciones/impacto-economico-en-nuevo-leon-ante-covid-19 (accessed May 12, 2020).

14. Xiong D, Zhang L, Watson GL, Sundin P, Bufford T, Zoller JA, et al. Pseudolikelihood based logistic regression for estimating COVID-19 infection and case fatality rates by gender, race, and age in California. Epidemics. (2020) 33:100418. doi: 10.1016/j.epidem.2020.100418

15. Instituto Nacional de Estadística, Geografía e Informática, Instituto Nacional de Salud Pública, Secretaría de Salud. Presentación de resultados. Encuesta Nacional de Salud y Nutrición. (2018). Available online at: https://ensanut. insp.mx/encuestas/ensanut2018/informes.php (accessed April 28, 2020).

16. Yadav R, Acharjee A, Salkar A, Bankar R, Palanivel V, Agrawal S, et al. Mumbai mayhem of COVID-19 pandemic reveals important factors that influence susceptibility to infection. EClinicalMedicine. (2021) 35:100841. doi: 10.1016/j.eclinm.2021.100841

17. Radzikowska U, Ding M, Tan G, Zhakparov D, Peng Y, Wawrzyniak P, et al. Distribution of ACE2, CD147, CD26, and other SARS-CoV-2 associated molecules in tissues and immune cells in health and in asthma, COPD, obesity, hypertension, and COVID-19 risk factors. Allergy. (2020) 24:282945. doi: 10.1111/all.14429

18. Wu Y, Li H, Zhang Z, Liang W, Zhang T, Tong Z, et al. Risk factors for mortality of coronavirus disease 2019 (COVID-19) patients during the early outbreak of COVID-19: a systematic review and meta-analysis. Ann Palliat Med. (2021) 10:70. doi: 10.21037/apm-20-2557

19. Du P, Li D, Wang A, Shen S, Ma Z, Li X. A systematic review and meta-analysis of risk factors associated with severity and death in COVID-19 patients. Can J Infect Dis Med Microbiol. (2021) 2021:6660930. doi: 10.1155/2021/6660930

20. Secretaría de Salud, Gobierno de México. Datos Abiertos Bases Históricas. Datos Abiertos Dirección General de Epidemiología. (2020). Available online at: https://www.gob.mx/salud/documentos/datos-abiertos-bases-historicasdireccion-general-de-epidemiologia (accessed September 24, 2021).
21. Gesesew HA, Koye DN, Fetene DM, Woldegiorgis M, Kinfu Y, Geleto $\mathrm{AB}$, et al. Risk factors for COVID-19 infection, disease severity and related deaths in Africa: a systematic review. BMJ Open. (2021) 11:e044618. doi: 10.1136/bmjopen-2020-044618

22. Hazeldine J, Lord JM. Immunesenescence: A predisposing risk factor for the development of COVID-19? Front Immunol. (2020) 11:573662. doi: 10.3389/fimmu.2020.573662

23. Falagas ME, Mourtzoukou EG, Vardakas KZ. Sex differences in the incidence and severity of respiratory tract infections. Respir Med. (2007) 101:184563. doi: 10.1016/j.rmed.2007.04.011

24. Acharya Y, Pant S, Gyanwali P, Dangal G, Karki P, Bista NR, et al. Gender disaggregation in COVID-19 and increased male susceptibility. J Nepal Health Res Counc. (2020) 18:345-50. doi: 10.33314/jnhrc.v18 i3.3108

25. Haitao T, Vermunt JV, Abeykoon J, Ghamrawi R, Gunaratne M, Jayachandran $\mathrm{M}$, et al. COVID-19 and sex differences: mechanisms and biomarkers. Mayo Clin Proc. (2020) 95:2189-203. doi: 10.1016/j.mayocp.2020. 07.024

26. Gao Y, Chen Y, Liu M, Shi S, Tian J. Impacts of immunosuppression and immunodeficiency on COVID-19: A systematic review and meta-analysis. $J$ Infect. (2020) 81:e93-5. doi: 10.1016/j.jinf.2020.05.017

27. Shah H, Khan MSH, Dhurandhar NV, Hegde V. The triumvirate: why hypertension, obesity, and diabetes are risk factors for adverse effects in patients with COVID-19. Acta Diabetol. (2021) 15:1-13. doi: 10.1007/s00592-020-01636-Z

Conflict of Interest: The authors declare that the research was conducted in the absence of any commercial or financial relationships that could be construed as a potential conflict of interest.

Copyright (c) 2021 Cordero-Franco, De La Garza-Salinas, Gomez-Garcia, MorenoCuevas, Vargas-Villarreal and González-Salazar. This is an open-access article distributed under the terms of the Creative Commons Attribution License (CC BY). The use, distribution or reproduction in other forums is permitted, provided the original author(s) and the copyright owner(s) are credited and that the original publication in this journal is cited, in accordance with accepted academic practice. No use, distribution or reproduction is permitted which does not comply with these terms. 